\title{
Liver Abscess due to Sewing Needle Perforation
}

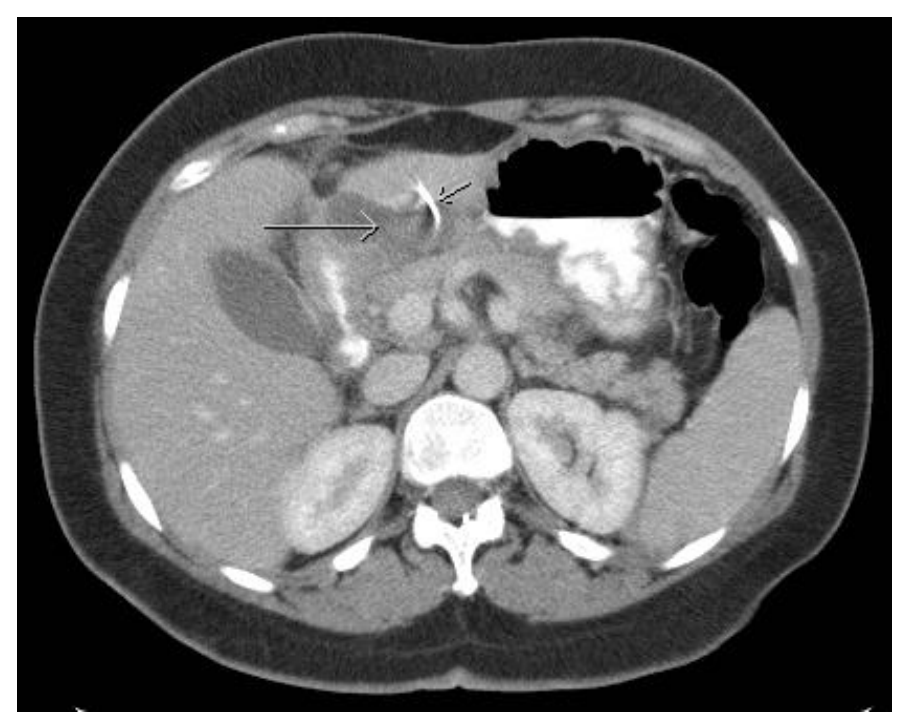

$\mathbf{A}$

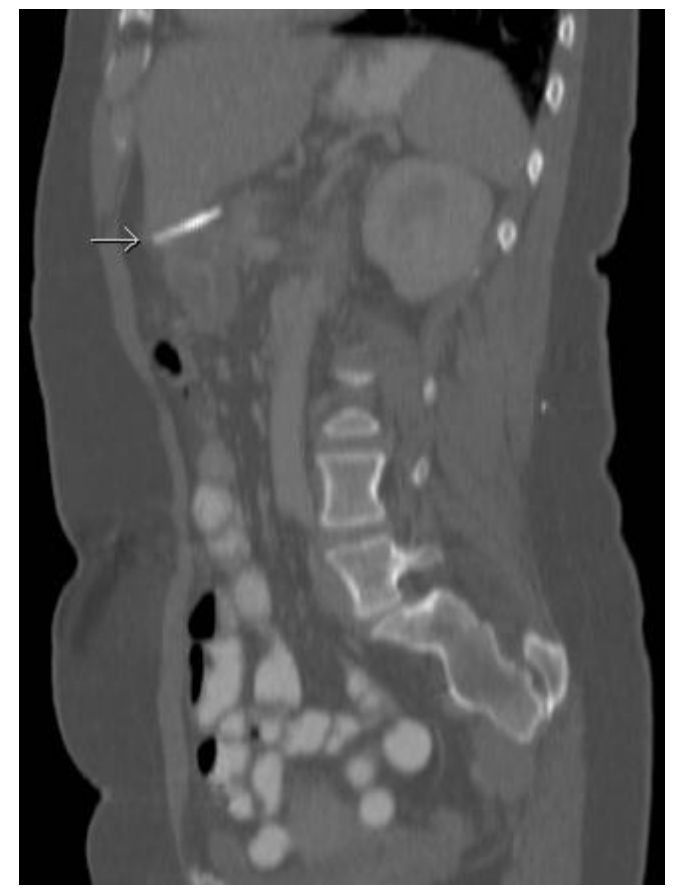

B

FIGURE 1. (A,B) Abdominal CT scan showing a foreign body perforating through the duodenum in the left liver lobe (small arrows) and a liver abscess (big arrow).

\section{Ewoud H. Jutte* and Huib A. Cense}

Department of Surgery, Red Cross Hospital, Beverwijk, The Netherlands

E-mail: ejutte@rkz.nl

Received May 31, 2010; Revised June 16, 2010; Accepted June 17, 2010; Published August 3, 2010

KEYWORDS: sewing needle perforation, liver abscess

A 45-year-old female was admitted to the hospital with a 1-week history of right upper abdominal pain and nausea. Ultrasonography showed a thickened duodenum with infiltration. Subsequent gastroscopy did not reveal any abnormalities. CT scan showed a foreign body perforation at the duodenum and a liver 
abscess (Fig. 1A,B). A diagnostic laparoscopy was performed. During the operation, the abscess was drained (Fig. 2A,B) and a sewing needle was removed (Fig. 3A,B). The patient claimed to have no recollection of swallowing the needle and made a quick recovery.

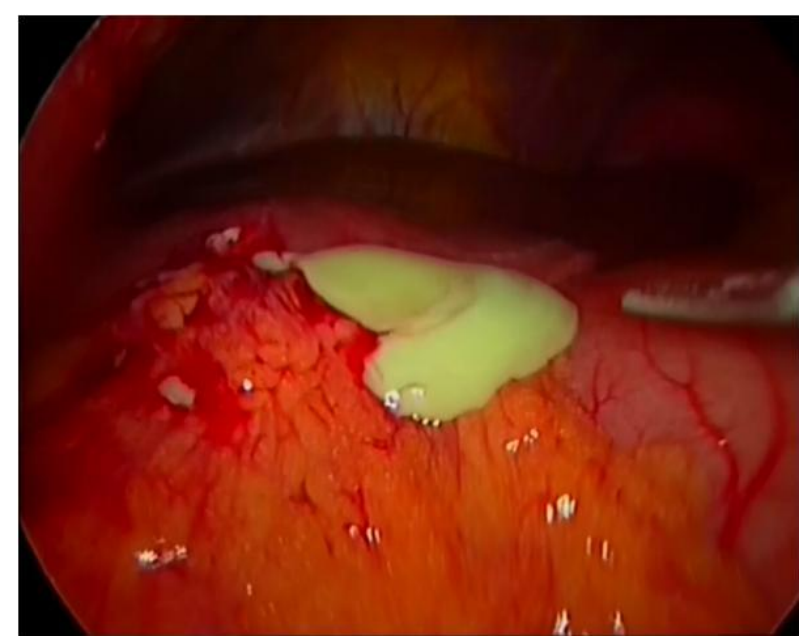

A

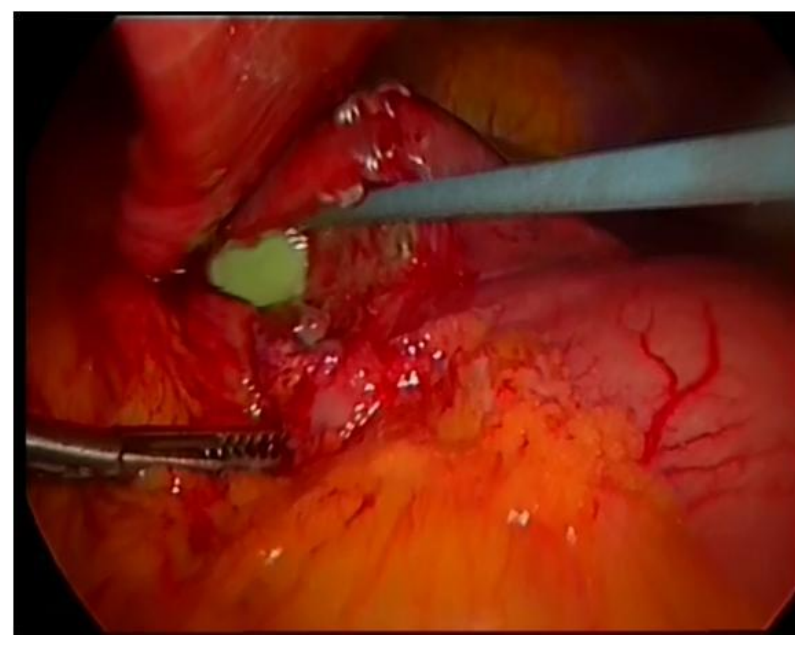

B

FIGURE 2. (A,B) Laparoscopic imaging showing the liver abscess, which was drained by a suction device.

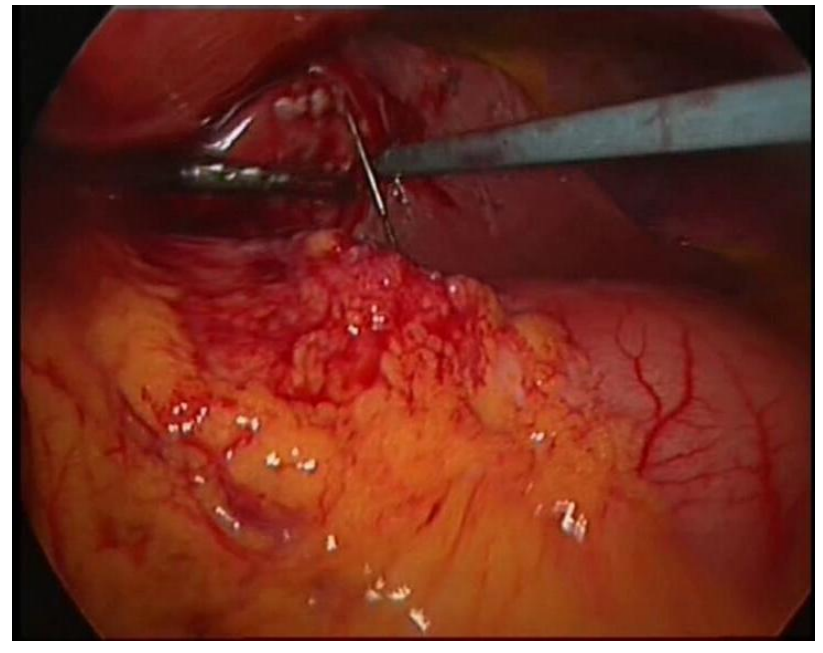

A

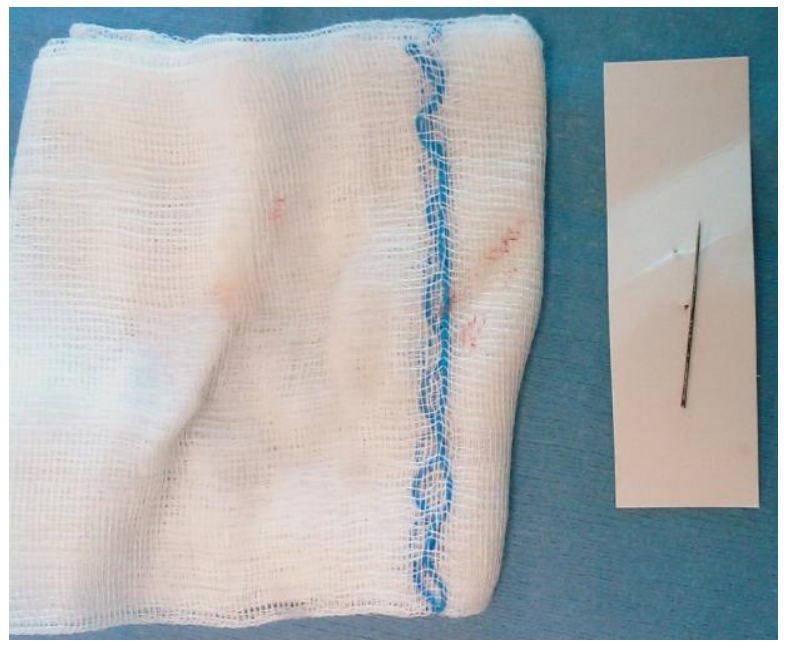

B

FIGURE 3. (A) Laparoscopic imaging showing the perforating sewing needle. (B) Postoperative image of the removed sewing needle, lying beside a $10-\times 10-\mathrm{cm}$ gauge.

Although rare, gastrointestinal perforations due to ingested foreign bodies most frequently occur at ileocecal, rectosigmoid, and duodenal regions[1]. Sewing needle perforations into the liver have been reported in children, adults, and psychiatric cases. Symptoms can vary from mild gastric pain to signs of peritonitis[2]. "Wait and see" is recommended for asymptomatic patients with no complications. Symptomatic patients (e.g., liver abscess) need surgical intervention[1,2,3]. 


\section{REFERENCES}

1. Bulakci, M., Agayev, A., Yanar, F., Sharifov, R., Taviloglu, K., and Ucar, A. (2009) Final destination of an ingested needle: the liver. Diagn. Interv. Radiol. [Epub ahead of print]

2. $\quad$ Feng, Q.Z., Wang, J., and Sun, H. (2009) A sewing needle in liver: a case report and review of the literature. Cases J. 2, 6520 .

3. Ariyuca, S., Doğan, M., Kaya, A., and Ay, M. (2009) An unusual cause of liver abscess. Liver Int. $29,1552$.

This article should be cited as follows:

Jutte, E.H. and Cense, H.A. (2010) Liver abscess due to sewing needle perforation. TheScientificWorldJOURNAL 10, 15321534. DOI 10.1100/tsw.2010.142. 


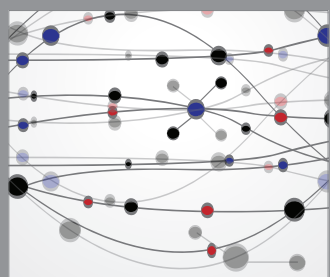

The Scientific World Journal
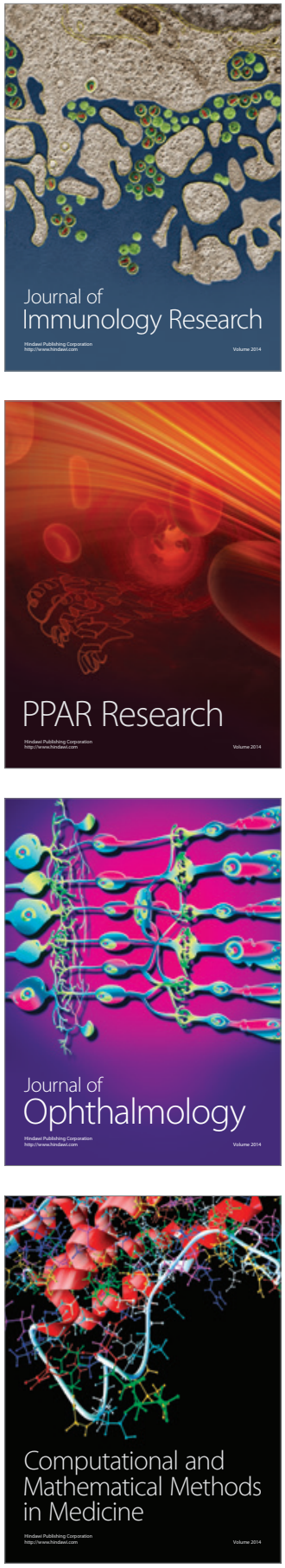

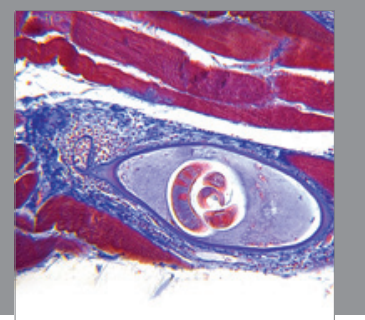

Gastroenterology

Research and Practice
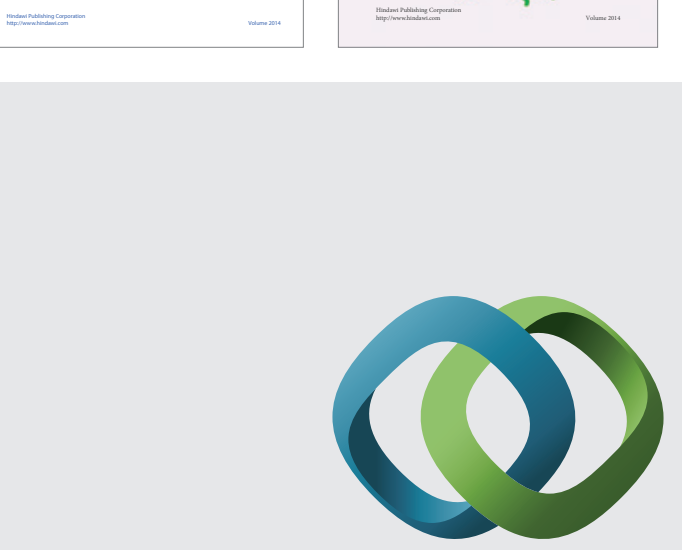

\section{Hindawi}

Submit your manuscripts at

http://www.hindawi.com
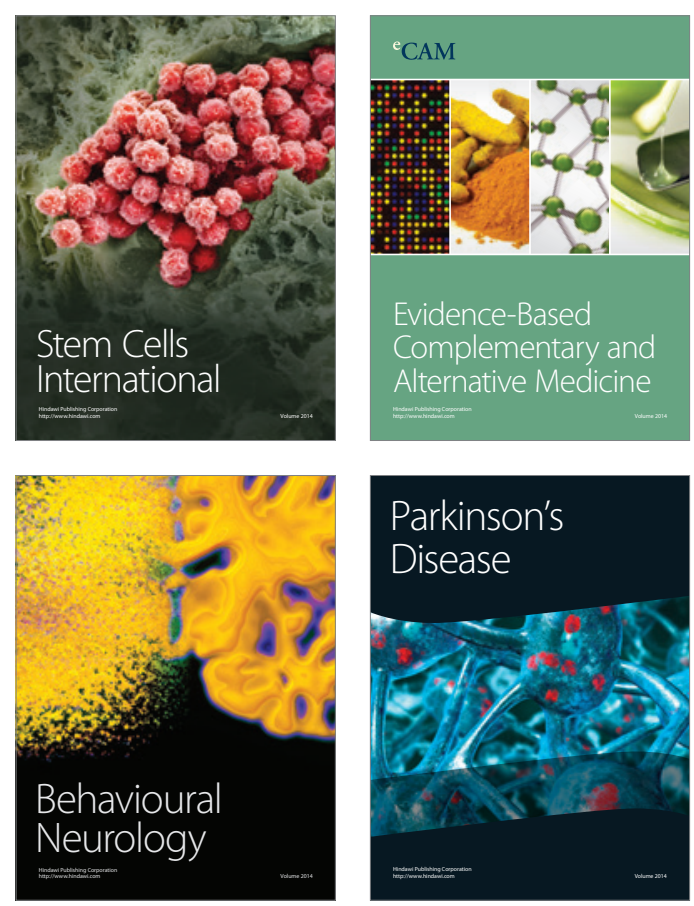

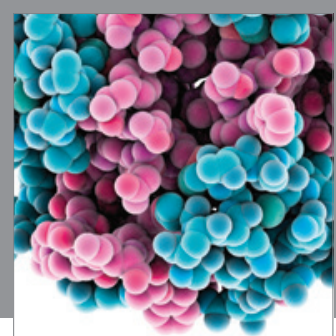

Journal of
Diabetes Research

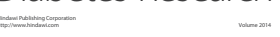

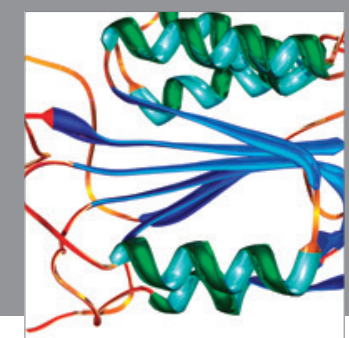

Disease Markers
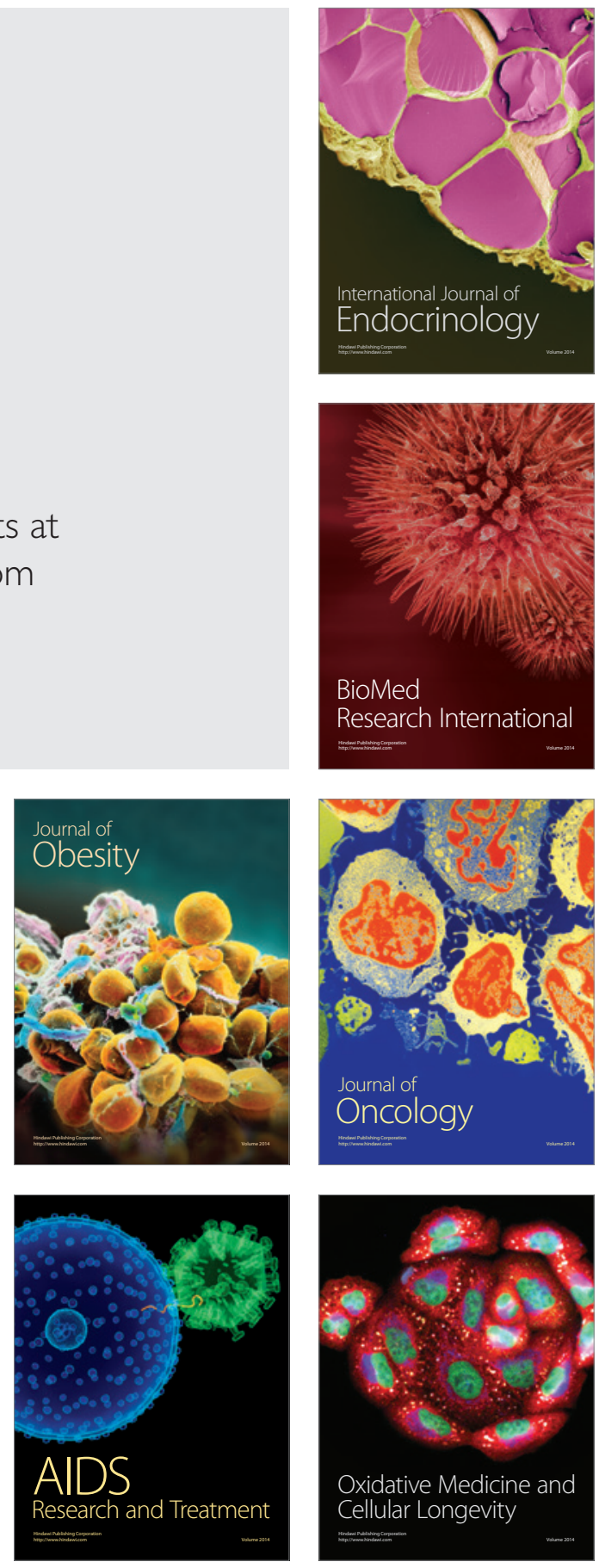